\title{
Moral Norm and the Two-Component Theory of Planned Behavior Model in Predicting Knowledge Sharing Intention: A Role of Mediator Desire
}

\author{
Chi-Cheng Huang1, Tzu-Hui Chen ${ }^{2}$ \\ ${ }^{1}$ Department of Information Management, Aletheia University, Taiwan \\ ${ }^{2}$ Department of Business Administration, Aletheia University, Taiwan \\ Email: chuang@mail.au.edu.tw
}

Received 26 August 2015; accepted 16 October 2015; published 19 October 2015

Copyright (C) 2015 by authors and Scientific Research Publishing Inc.

This work is licensed under the Creative Commons Attribution International License (CC BY).

http://creativecommons.org/licenses/by/4.0/

(c) (i) Open Access

\begin{abstract}
Knowledge sharing is becoming an increasingly popular area and has been extensively discussed in knowledge management literature. The theory of planned behavior (TPB) is a leading theoretical model of cognitive determinants of behavior that has been shown to predict knowledge sharing. Although the TPB has been used in predicting knowledge sharing, integrating additional variables or theories may heighten the predictive ability of the TPB. This study proposes an integrated model that considers desire and moral norm in a two-component TPB model for predicting knowledge sharing intention. Our models are assessed by using data from a sample of 220 participants in one of the largest credit cooperatives in Taiwan and analyzed using the partial least squares (PLS) method. The results of this study indicate that 1) moral norm is an important variable in predicting desire toward knowledge sharing; 2) desire fully mediates the relationship between cognitive attitude and intention; and 3) desire partially mediates the relationships between affective attitude, self-efficacy, moral norm and intention. This study also discusses the implications of knowledge sharing intention.
\end{abstract}

Keywords

Knowledge Sharing, Desire, Moral Norm, Two-Component TPB

\section{Introduction}

Knowledge sharing is the behavior characterized by an individual disseminating his acquired knowledge to other

How to cite this paper: Huang, C.-C., \& Chen, T.-H. (2015). Moral Norm and the Two-Component Theory of Planned Behavior Model in Predicting Knowledge Sharing Intention: A Role of Mediator Desire. Psychology, 6, 1685-1699.

http://dx.doi.org/10.4236/psych.2015.613165 
members within an organization (Ryu et al., 2003). How knowledge can be shared as an organizational asset is a challenging issue in KM. Previous literature has emphasized various factors influencing individuals’ willingness to share knowledge, such as extrinsic and intrinsic motivation, organization climate, costs and benefits, personality traits, social cognition, social capital or information technology (Bock et al., 2005; Chiu et al., 2006; Engelmann \& Hesse, 2011; Hsu et al., 2007; Kankanhalli et al., 2005; Matzler et al., 2008; Wasko \& Faraj, 2005). Although contemporary knowledge sharing research has yielded extensive explanations regarding factors affecting the sharing of knowledge in recent years, these factors are still worthy of being explored. This study will adopt the theory of planned behavior (TPB) to predict knowledge sharing intention because the TPB is perhaps the most influential theory for the prediction of social behaviors (Rivis et al., 2009).

The TPB, which was developed by Ajzen (1991), has become a primary theory to explain intention and actual behavior in different areas. TPB regards attitude, subjective norm, and perceived behavioral control (PBC) as three factors useful for predicting intention and actual behavior. Armitage \& Conner (2001) examined the efficacy of the TPB and indicated that the TPB accounted for $27 \%$ and $39 \%$ of variance in behavior and intention, respectively. Such examination implies that $61 \%$ of the variance in intentions remains unexplained by attitude, subjective norm, or PBC. To better understand of the TPB, many studies have incorporated additional variables into the TPB or used the two-component TPB (Conner \& Sparks, 2005) to explain intention and actual behavior. The two-component TPB accounts for the differentiated components of the core TPB constructs of attitude, subjective norm, and PBC. Attitude is separated into affective and cognitive components. Subjective norm is separated into injunctive norm and descriptive norm. PBC is separated into self-efficacy and perceived controllability. The results of Courneya et al. (2006) reported that the explanation ability of two-component TPB is superior to the traditional TPB. In addition to two-component TPB, Conner \& Armitage (1998) suggested the importance of moral norm in improving the explanation ability of the TPB. Moral norm is regarded as an individual's perception of the moral correctness or incorrectness of performing a behavior (Ajzen, 1991; Sparks, 1994). We suggest that moral norm may positively influence knowledge sharing intention. Knowledge can be considered a public good (Cabrera \& Cabrera, 2002). Such a viewpoint indicates that knowledge belongs not to employees individually, but to the whole organization. Employees may have a tendency to share their knowledge based on a sense of public duty or concern for their organizations. Such shared knowledge can spread throughout the organization without losing its value and all employees can use it. When employees consider knowledge a public good, employees are motivated to share it with others due to a sense of moral obligation rather than self-interest (Ardichvili et al., 2003; Wasko \& Faraj, 2000). To our knowledge, the effect of moral norm on knowledge sharing intention is rarely empirically examined in the TPB. Thus, the first goal of this study is to empirically examine whether the two-component TPB combined with moral norm can predict knowledge sharing intention. This examination may extend the application of moral norm in knowledge sharing and contribute to TPB literature.

Though the TPB may provide a reason for predicting behavior, the TPB does not incorporate explicit motivational content (e.g., desire), which has been relatively overlooked by the TPB as a possible inducement of intention to actual behavior. Desire represents the motivational state of mind wherein appraisals and reasons to act are transformed into a motivation to do so (Perugini \& Bagozzi, 2001). For example, an individual intends to share knowledge only if he or she is motivated to share knowledge. From this perspective, Perugini \& Bagozzi (2001) contended that desire fully mediates the relationships between attitude, subjective norm, PBC and intention. Yet, the results of several studies (e.g., Kovac \& Rise, 2011; Leone et al., 2004; Shaw et al., 2007) did not support Perugini and Bagozzi's conclusions. Because there are inconsistent findings in previous studies, the mediating role of desire is an excellent candidate for re-examination. Thus, the second goal of this study is to examine whether the constructs of two-component TPB and moral norm can indirectly influence knowledge sharing intention through desire. We try to discriminate the role of desire and thereby contribute to TPB literature by clarifying the mediating role of desire in the two-component TPB.

\section{Literature Review}

\subsection{The Theory of Planned Behavior (TPB) and Moral Norm}

The theory of planned behavior (TPB) (Ajzen, 1991) was developed to explain behavior under incomplete volitional control. According to the TPB, intention to perform a behavior is determined by attitude, subjective norm and perceived behavioral control (PBC), which in turn, influences the behavior of interest, while PBC typically 
also has an effect on behavior. Ajzen (1991) mentioned that intention indicates to what extent people want to perform the behavior and how much effort they are prepared to exert to perform it. Attitude refers to people's positive or negative evaluation of their performing the behavior. Subjective norm refers to people's perceptions of approval or disapproval from significant others for performing the behavior. PBC refers to people's appraisals of the ease or difficulty of performing the behavior. Positive attitude toward a behavior, positive subjective norm, and high PBC over a behavior are assumed to induce a strong intention to perform that behavior. When individuals have stronger intentions, they are more likely to perform the behavior. The TPB has been applied successfully to a wide range of behaviors, and meta-analytic reviews support the theory's predictions (Rivis et al., 2009). Specifically, previous studies (e.g., Bock et al., 2005; Chen \& Chen, 2009; Kuo \& Young, 2008; Lin \& Lee, 2004; Ryu et al., 2003) have used the TPB in predicting knowledge sharing; their findings indicated the TPB has good predictive ability for knowledge sharing.

Although attitude, subjective norm and PBC are traditionally measured as single concepts, Ajzen (2002) suggests that each TPB construct comprises two specific subcomponents. Attitude is hypothesized to be composed of affective attitude (e.g., pleasant/unpleasant) and cognitive attitude (e.g., useful/useless). Subjective norm is hypothesized to be composed of an injunctive component (e.g., whether one believes their social network wants them to perform the behavior) and a descriptive component (e.g., whether one's social network performs a behavior). PBC is hypothesized to be composed of self-efficacy (e.g., ease/difficulty, confidence) and perceived controllability (e.g., personal control over behavior, appraisal of whether the behavior is completely up to the individual) (Ajzen, 2002; Rhodes \& Courneya, 2003). To understand the conceptualization of these component relationships within the TPB, several researchers (e.g., Courneya et al., 2006; Elliott \& Ainsworth, 2012; Fen \& Sabaruddin, 2008; Hagger \& Chatzisarantis, 2005; Ryan \& Courneya, 2003) have begun to use the two-component TPB in predicting social behaviors and have suggested that the two-component TPB is superior to Ajzen's (1991) traditional TPB model. Although Kuo \& Young (2008) first used attitude, subjective norm and two-dimensional PBC (self-efficacy, controllability) in predicting knowledge sharing, overall two-component TPB is rarely applied in knowledge sharing literature.

To extend the TPB, Conner \& Armitage (1998) suggested the importance of moral norm in the TPB. Moral norm is regarded as an individual's perception of the moral correctness or incorrectness of performing a behavior (Ajzen, 1991; Sparks, 1994). Moral norm should have an important influence on the performance of those behaviors with a moral or ethical dimension, and work in parallel with attitude, subjective norm, and PBC (Ajzen, 1991; Conner \& Armitage, 1998). Integrating moral norm into the TPB explains an average of $4 \%$ of the variance in the prediction of intention over and above TPB constructs (Armitage \& Conner, 2001; Conner \& Armitage, 1998). Previous empirical studies (e.g., Chu \& Chiu, 2003; Conner et al., 2007; Godin et al., 2005; Lam, 1999; Rivis et al., 2009) have supported a positive relationship between moral norm and intention. Therefore, we propose the following hypotheses:

$H_{1}$ : Two-component TPB is positively associated with knowledge sharing intention.

$\mathrm{H}_{2}$ : Moral norm is positively associated with knowledge sharing intention.

\subsection{The Role of Desire in the TPB}

It has been argued that the TPB fails to consider how intention becomes energized or motivated (Bagozzi, 1992; Fazio, 1995; Han \& Ryu, 2012). The constructs in the TPB provide rational reasons for acting, it is claimed, and may be significantly correlated with intention but do not incorporate explicit motivational content needed to induce an intention to act (Bagozzi \& Dholakia, 2006; Perugini \& Bagozzi, 2001). For example, an individual may feel normative pressure or have wherewithal to sustain sharing knowledge; however, he or she may not want to share knowledge and therefore not form an intention to share knowledge. Thus, the rationale for including desire as an additional predictor of intention is that attitude, subjective norm and PBC may not adequately explain the development of intention (Langdridge et al., 2007).

Taylor et al. (2009) and Perugini \& Bagozzi (2001) indicated that desire represents the motivational state of mind wherein appraisals and reasons to act are transformed into a motivation to do so. Some philosophers of action have even argued that "someone intends to do something only if he is motivated to do it" (Davis, 1984). According to the theory of self-regulation, Bagozzi (1992) claimed that desire is hypothesized as being a proximal cause of intention. Some philosophers maintain that desire has a particular type of relationship to intention in the sense that, once one is aware of and accepts his or her desire to act, this will motivate him or her to form 
an intention to act (Bagozzi \& Dholakia, 2006). From a practical perspective, the role of desire as the main direct predictor of intention enables researchers and practitioners to try to influence desire to effectively change or strengthen intention (Leone et al., 2004). If evaluations are strong enough, attitude, subjective norm and PBC will lead to intention to perform or not to perform the target act. However, evaluative appraisals do not imply motivational commitment, and intention cannot arise without any motivational push (i.e., desire) (Leone et al., 1999). According to Perugini \& Bagozzi (2001), attitude, subjective norm and PBC provide reasons for acting but do not incorporate the explicit motivational content needed to induce an intention to act. Thus, they suggested that desire may be construed as the mediator of the relationships among attitude, subjective norm, PBC and intention. Previous literature (Armitage \& Conner, 2001; Richetin et al., 2008; Perugini \& Bagozzi, 2001; Perugini \& Conner, 2000) has examined the efficacy of the TPB and has indicated that attitude, subjective norm and $\mathrm{PBC}$ have effects on desire and, in turn, influence intention. In addition, moral norm provides moral reasons for acting but does not incorporate explicit motivational content needed to induce an intention to act. Like subjective norm, moral norm refers to expectations that one will behave in a certain way (Langdridge et al., 2007). Similarly to subjective norm, moral norm may induce an ethical behavior through desire. That is, desire may be considered the mediator of the relationship between moral norm and intention. Therefore, we propose the following hypotheses:

$H_{3}$ : Desire mediates the relationship between two-component TPB and knowledge sharing intention.

$\mathrm{H}_{4}$ : Desire mediates the relationship between moral norm and knowledge sharing intention.

\section{Research Methodology}

In this study, we use the two-component TPB model to predict knowledge sharing intention. We hypothesize that desire mediates the relationships between TPB constructs (affective and cognitive attitudes, injunctive and descriptive norms, self-efficacy and perceived controllability), moral norm and knowledge sharing intention. Figure 1 describes our research model. We tested the research model by administrating a questionnaire survey to the employees of a credit cooperative in Taiwan.

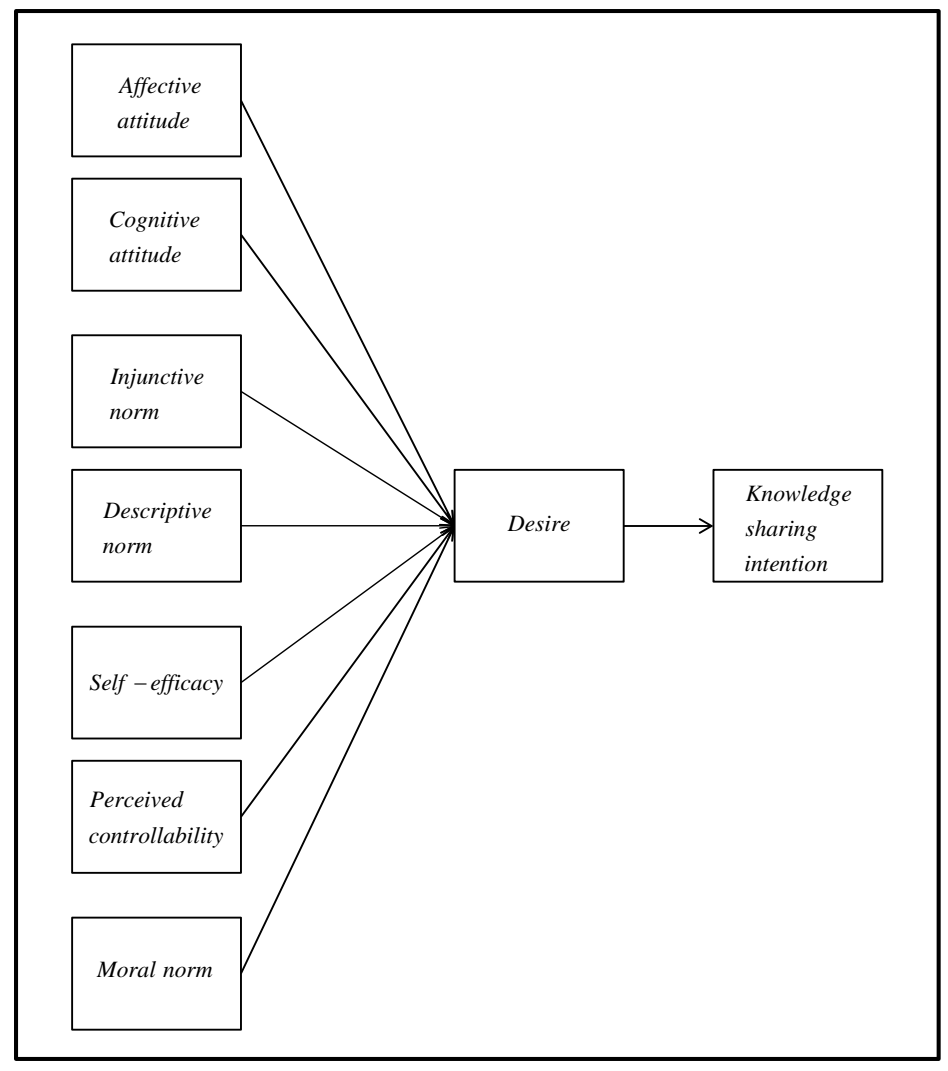

Figure 1. Research model. 
The survey measures for this study were derived from the following previously published studies: twocomponent TPB construct questions were used from Courneya et al. (2006) and Rhodes et al. (2003); desire from Perugini \& Bagozzi (2001); and moral norm from Langdridge et al. (2007). We adapted the survey measures in accordance with the context of knowledge sharing. All of the constructs were measured using seven-point Likert scales ranging from "strongly disagree" (1) to "strongly agree" (7). Ten credit cooperative professionals were asked to refine the preliminary measurement questions. These experts examined whether the questions might be interpreted definitively, and we accepted their suggestions for making the questions more relevant. Refining the questions based on experts' suggestions ensured the content validity of the questionnaire.

We investigated credit cooperatives as the research target. Credit cooperatives are important financial institutions for regional finance in Taiwan and are based on mutual support of owners and workers at small and medium-sized firms. Credit cooperatives provide loan and banking services. For example, they accept deposits from members of the cooperative, government units, or profit and non-profit sectors. They also lend and discount bills to members and certain non-members, and engage in payments associated with securities transactions (Fukuyama et al., 1999). Managing knowledge is as important to banking institutions as it is for any other type of organization because banks do not sell goods but instead services and, more specifically, knowledge (Chatzoglou \& Vraimaki, 2009). To face increasing competitiveness from domestic and foreign banks, credit cooperatives may need to encourage employees to share knowledge because knowledge sharing has proved to be helpful for organizational performance. Knowledge sharing intention among employees has been widely examined in various industries. Yet, to our knowledge, exploring knowledge sharing intention among employees is rare in credit cooperatives. Thus, this study may contribute to KM literature by examining the factors influencing knowledge sharing intention in credit cooperatives.

Our refined questionnaire was used to collect the study's data from the Fifth Credit Cooperation of Taipei in Taiwan. The Fifth Credit Cooperation of Taipei was first established in 1918 and is one of the largest credit cooperatives in Taiwan. Because one of the authors served as a deputy manager in the Fifth Credit Cooperation of Taipei, we decided to let her distribute the questionnaire. She distributed the questionnaire to all 241 employees in 13 branches. To show appreciation for the employees' assistance, we offered them nonmonetary gifts. As a result, a total of 220 employees returned their completed questionnaires (91.3\% response rate). Because we focused on investigating the perceptions of employees in the Fifth Credit Cooperation of Taipei, we did not access employees who serve in other financial institutes. Thus, such investigation may lead to self-selection bias. Such bias may be a threat to generalization about our findings and we should interpret our findings with caution. A majority of the respondents were female (57.7\%). In addition, many of the respondents were between the ages of 41 and 50 (38.2\%), and between 31 and 40 (35.5\%). A large portion of the respondents had work experience of between 5 and 10 years (23.3\%), followed by more than 20 years (22.7\%). Many of the respondents graduated from college (39.6\%), followed by high school (38.6\%). Moreover, $72.3 \%$ of the respondents were employees, while $27.7 \%$ of the respondents had managerial position.

We used partial least squares (PLS) to analyze our research model. PLS path modeling is widely used not only in management research but also in virtually all social sciences disciplines (Henseler et al., 2014). PLS is a causal modeling approach aimed at maximizing the explained variance of dependent latent constructs (Hair et al., 2011). Haenlein \& Kaplan (2004) indicated that a PLS model consists of a structural part, which describes the relationships between the latent variables, and a measurement part, which shows how the latent variables and their indicators are related. We estimated structural and measurement parts in our research model using Smart PLS software (Ringle et al., 2005).

\section{Results}

\subsection{Measurement Model}

We initially conducted the PLS analysis to examine item reliability in our research model. Table 1 shows the loadings of the measures to their respective constructs. Henseler et al. (2009) suggested that construct item loadings should exceed 0.7. Thus, we can confirm that the overall measurement items have good item reliability. In addition, we estimated convergent validity by examining the composite reliability (CR) and average variance extracted (AVE) from the measures in Table 2. The AVE should be higher than 0.5, and the CR should not be lower than 0.6 (Henseler et al., 2009). Table 2 indicates that all AVEs and CRs exceed the cut-off values mentioned above. Thus, we can confirm that the measurement models have good convergent validity. Moreover, we 
Table 1. Construct item loadings.

\begin{tabular}{lccc}
\hline \multicolumn{1}{c}{ Construct } & Item & Loading & t-value \\
\hline & AA1 & $0.956^{* *}$ & 213.911 \\
Affective attitude (AA) & AA2 & $0.959^{* *}$ & 209.558 \\
& AA3 & $0.957^{* *}$ & 228.667 \\
Cognitive attitude (CA) & CA1 & $0.933^{* *}$ & 105.447 \\
& CA2 & $0.930^{* *}$ & 98.624 \\
Injunctive norm (IN) & CA3 & $0.926^{* *}$ & 113.956 \\
& IN1 & $0.921^{* *}$ & 103.830 \\
Descriptive norm (DN) & IN2 & $0.940^{* *}$ & 111.716 \\
& IN3 & $0.918^{* *}$ & 51.450 \\
Self-efficacy (SE) & DN1 & $0.935^{* *}$ & 120.996 \\
& DN2 & $0.933^{* *}$ & 122.442 \\
Perceived controllability (PC) & DN3 & $0.954^{* *}$ & 180.160 \\
& SE1 & $0.930^{* *}$ & 116.977 \\
Knowledge sharing intention (KSI) & SE2 & $0.955^{* *}$ & 256.562 \\
& SE3 & $0.945^{* *}$ & 193.458 \\
Moral norm (MN) & PC1 & $0.858^{* *}$ & 56.870 \\
& PC2 & $0.937^{* *}$ & 164.401 \\
& PC3 & $0.939^{* *}$ & 187.844 \\
& MN1 & $0.873^{* *}$ & 76.131 \\
& MN2 & $0.872^{* *}$ & 81.631 \\
& MN3 & $0.878^{* *}$ & 60.897 \\
& KSI1 & $0.931^{* *}$ & 163.375 \\
& KSI3 & $0.943^{* *}$ & 145.811 \\
& & $0.939^{* *}$ & 139.327 \\
\hline
\end{tabular}

Note: ${ }^{* * *} P<0.01$.

Table 2. Convergent validity and discriminant validity.

\begin{tabular}{cccccccccc}
\hline & AA & CA & IN & DN & SE & PC & MN & D & KSI \\
\hline AA & 0.96 & & & & & & & & \\
CA & $0.75^{* *}$ & 0.93 & & & & & & & \\
IN & $0.68^{* *}$ & $0.60^{* *}$ & 0.93 & & & & & & \\
DN & $0.59^{* *}$ & $0.49^{* *}$ & $0.72^{* *}$ & 0.94 & & & & & \\
SE & $0.49^{* *}$ & $0.37^{* *}$ & $0.55^{* *}$ & $0.41^{* *}$ & 0.94 & & & & \\
PC & $0.41^{* *}$ & $0.31^{* *}$ & $0.47^{* *}$ & $0.42^{* *}$ & $0.68^{* *}$ & 0.91 & & & \\
MN & $0.49^{* *}$ & $0.37^{* *}$ & $0.46^{* *}$ & $0.34^{* *}$ & $0.45^{* *}$ & $0.40^{* *}$ & 0.87 & & \\
D & $0.52^{* *}$ & $0.28^{* *}$ & $0.53^{* *}$ & $0.42^{* *}$ & $0.66^{* *}$ & $0.56^{* *}$ & $0.54^{* *}$ & 0.95 & \\
KSI & $0.57^{* *}$ & $0.34^{* *}$ & $0.50^{* *}$ & $0.44^{* *}$ & $0.67^{* *}$ & $0.53^{* *}$ & $0.62^{* *}$ & $0.83^{* *}$ & 1 \\
AVE & 0.92 & 0.87 & 0.86 & 0.89 & 0.89 & 0.83 & 0.76 & 0.91 & 0.88 \\
CR & 0.97 & 0.95 & 0.95 & 0.96 & 0.96 & 0.94 & 0.91 & 0.97 & 0.96 \\
Mean & 5.96 & 6.15 & 5.72 & 5.58 & 5.39 & 5.44 & 5.27 & 5.16 & 5.09 \\
SD & 0.94 & 0.83 & 0.97 & 1.16 & 1.08 & 1.09 & 0.97 & 1.19 & 1.14 \\
\hline
\end{tabular}

Note: The italic numbers in the diagonal row are square roots of average variance extracted. ${ }^{* *} P<0.01$. 
estimated discriminant validity following the suggestions of Hair et al. (2014). Table 2 indicates that the square root of the AVE of each construct is higher than its highest correlation with any other construct, thereby confirming the discriminant validity in the research model. We further constructed a cross-loadings table (see Table 3), as suggested by Gefen et al. (2000). Each item loading in the table is much higher on its assigned construct than on the other constructs, supporting adequate convergent and discriminant validity.

\subsection{Structural Model}

Following the suggestions of Hair et al. (2011), we performed a bootstrapping procedure (with 5000 sub-samples) to test the statistical significance of each path coefficient in the research model (see Figure 2). In addition, Table 4

Table 3. Cross loadings.

\begin{tabular}{|c|c|c|c|c|c|c|c|c|c|}
\hline & $\mathrm{AA}$ & CA & IN & $\mathrm{DN}$ & SE & PC & $\mathrm{MN}$ & $\mathrm{D}$ & KSI \\
\hline AA1 & 0.93 & 0.68 & 0.55 & 0.45 & 0.33 & 0.31 & 0.35 & 0.24 & 0.30 \\
\hline AA2 & 0.93 & 0.70 & 0.57 & 0.48 & 0.33 & 0.28 & 0.32 & 0.25 & 0.30 \\
\hline AA3 & 0.93 & 0.71 & 0.54 & 0.43 & 0.36 & 0.29 & 0.37 & 0.29 & 0.35 \\
\hline CA1 & 0.70 & 0.96 & 0.62 & 0.53 & 0.46 & 0.39 & 0.46 & 0.52 & 0.55 \\
\hline CA2 & 0.72 & 0.96 & 0.64 & 0.55 & 0.46 & 0.38 & 0.49 & 0.48 & 0.54 \\
\hline CA3 & 0.73 & 0.96 & 0.68 & 0.60 & 0.48 & 0.41 & 0.45 & 0.50 & 0.55 \\
\hline IN1 & 0.55 & 0.62 & 0.92 & 0.63 & 0.55 & 0.46 & 0.45 & 0.48 & 0.46 \\
\hline IN2 & 0.54 & 0.65 & 0.94 & 0.65 & 0.50 & 0.43 & 0.44 & 0.49 & 0.49 \\
\hline IN3 & 0.56 & 0.61 & 0.92 & 0.71 & 0.47 & 0.44 & 0.39 & 0.50 & 0.46 \\
\hline DN1 & 0.46 & 0.54 & 0.69 & 0.94 & 0.43 & 0.41 & 0.28 & 0.41 & 0.42 \\
\hline DN2 & 0.47 & 0.57 & 0.68 & 0.93 & 0.37 & 0.42 & 0.36 & 0.41 & 0.43 \\
\hline DN3 & 0.45 & 0.54 & 0.64 & 0.95 & 0.37 & 0.37 & 0.31 & 0.37 & 0.39 \\
\hline SE1 & 0.36 & 0.42 & 0.51 & 0.41 & 0.93 & 0.64 & 0.36 & 0.56 & 0.57 \\
\hline SE2 & 0.34 & 0.46 & 0.50 & 0.37 & 0.95 & 0.66 & 0.45 & 0.67 & 0.67 \\
\hline SE3 & 0.35 & 0.50 & 0.53 & 0.40 & 0.95 & 0.66 & 0.45 & 0.63 & 0.66 \\
\hline PC1 & 0.26 & 0.31 & 0.34 & 0.34 & 0.50 & 0.86 & 0.34 & 0.44 & 0.40 \\
\hline PC2 & 0.28 & 0.38 & 0.48 & 0.40 & 0.71 & 0.94 & 0.37 & 0.54 & 0.54 \\
\hline РC3 & 0.32 & 0.42 & 0.47 & 0.41 & 0.66 & 0.94 & 0.37 & 0.54 & 0.52 \\
\hline MN1 & 0.35 & 0.38 & 0.38 & 0.24 & 0.40 & 0.34 & 0.87 & 0.44 & 0.50 \\
\hline MN2 & 0.33 & 0.47 & 0.41 & 0.29 & 0.40 & 0.37 & 0.87 & 0.49 & 0.60 \\
\hline MN3 & 0.30 & 0.42 & 0.42 & 0.35 & 0.38 & 0.32 & 0.88 & 0.49 & 0.53 \\
\hline D1 & 0.27 & 0.51 & 0.51 & 0.41 & 0.64 & 0.53 & 0.53 & 0.95 & 0.77 \\
\hline D2 & 0.26 & 0.49 & 0.50 & 0.42 & 0.61 & 0.53 & 0.49 & 0.96 & 0.78 \\
\hline D3 & 0.28 & 0.49 & 0.49 & 0.39 & 0.63 & 0.54 & 0.53 & 0.95 & 0.82 \\
\hline KSI1 & 0.27 & 0.54 & 0.48 & 0.43 & 0.61 & 0.48 & 0.53 & 0.81 & 0.93 \\
\hline KSI2 & 0.35 & 0.54 & 0.50 & 0.39 & 0.64 & 0.50 & 0.63 & 0.77 & 0.94 \\
\hline KSI3 & 0.34 & 0.53 & 0.45 & 0.42 & 0.65 & 0.52 & 0.59 & 0.75 & 0.94 \\
\hline
\end{tabular}




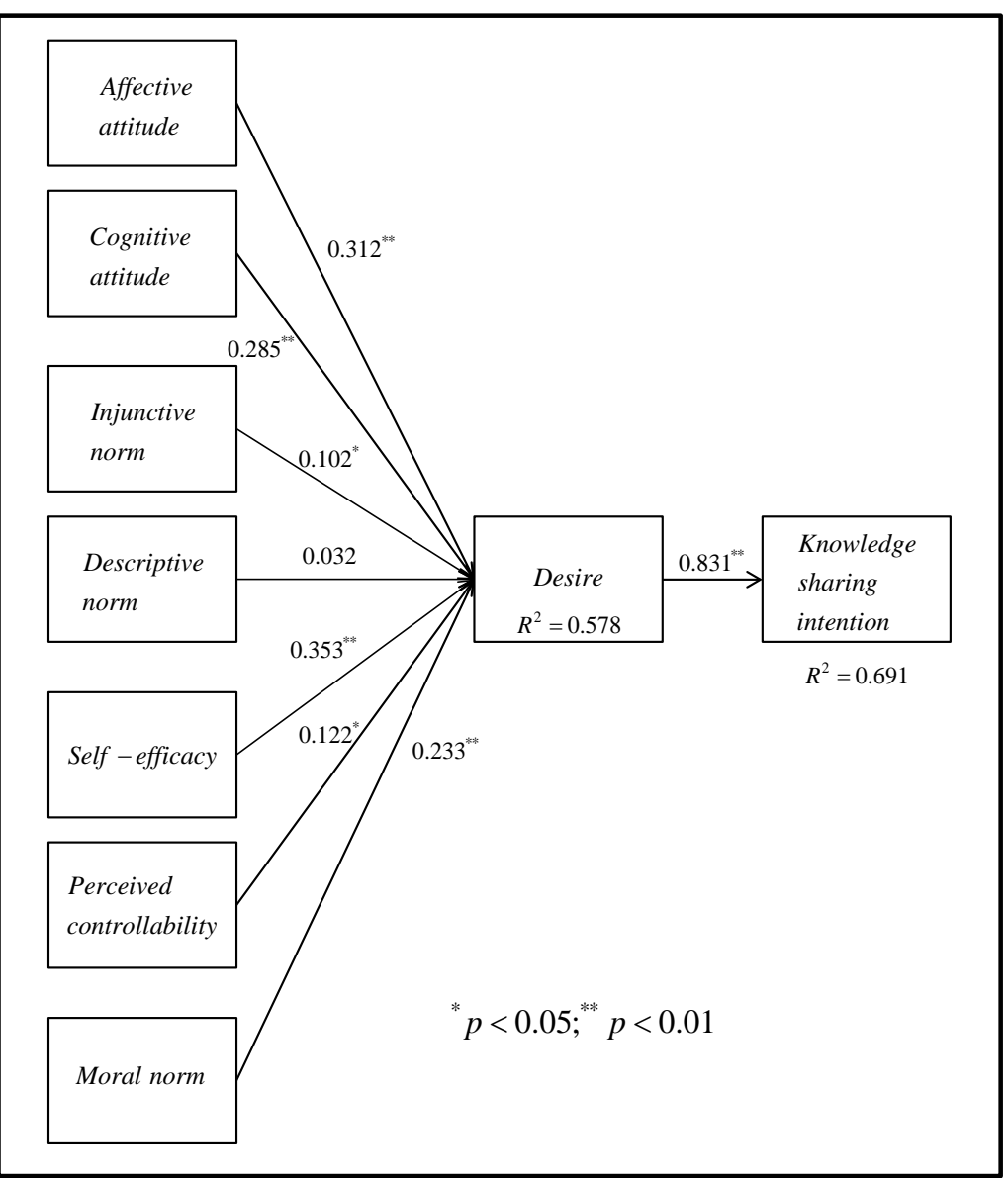

Figure 2. The results of PLS analysis.

Table 4. Parameter estimation of the PLS Models.

\begin{tabular}{|c|c|c|c|}
\hline Construct & Model 1 & Model 2 & Model 3 \\
\hline \multicolumn{4}{|l|}{ Dependent variable: Desire } \\
\hline Affective attitude & $0.312^{* *}$ & & $0.311^{* *}$ \\
\hline Cognitive attitude & $0.285^{* *}$ & & $0.285^{* *}$ \\
\hline Injunctive norm & $0.102^{*}$ & & $0.101^{*}$ \\
\hline Descriptive norm & 0.032 & & 0.033 \\
\hline Self-efficacy & $0.353^{* *}$ & & $0.353^{* *}$ \\
\hline Perceived controllability & $0.122^{*}$ & & $0.122^{*}$ \\
\hline Moral norm & $0.233^{* *}$ & & $0.234^{* *}$ \\
\hline$R^{2}$ & 0.578 & & 0.577 \\
\hline \multicolumn{4}{|c|}{ Dependent variable: Knowledge sharing intention } \\
\hline Desire & $0.831^{* *}$ & & $0.555^{* *}$ \\
\hline Affective attitude & & $0.332^{* *}$ & $0.163^{*}$ \\
\hline Cognitive attitude & & $0.205^{* *}$ & 0.050 \\
\hline Injunctive norm & & 0.058 & 0.013 \\
\hline Descriptive norm & & 0.091 & 0.072 \\
\hline Self-efficacy & & $0.397^{* *}$ & $0.201^{* *}$ \\
\hline Perceived controllability & & 0.045 & 0.023 \\
\hline Moral norm & & $0.340^{* *}$ & $0.208^{* *}$ \\
\hline$R^{2}$ & 0.691 & 0.636 & 0.765 \\
\hline
\end{tabular}

Model 1: original model (Figure 1); Model 2: model without desire; Model 3: full model including direct paths between affective/cognitive attitude, injunctive/descriptive norm, self-efficacy/perceived controllability, moral norm and knowledge sharing intention. ${ }^{*} P<0.05 ;{ }^{* *} P<0.01$. 
indicates that two-component TPB has effect on knowledge sharing intention. In particular, affective attitude, cognitive attitude, self-efficacy, and moral norm have effects on knowledge sharing intention. Thus, $H_{1}$ was partially supported and $\mathrm{H}_{2}$ was supported. In addition, we followed the procedure suggested by Baron \& Kenny (1986) to examine the mediating effect of desire. We performed a PLS analysis to assess the effect of affective and cognitive attitudes, injunctive and descriptive norms, self-efficacy and controllability, and moral norm on knowledge sharing intention in the absence of desire. Our findings indicated that affective attitude, cognitive attitude, self-efficacy, and moral norm had an effect on knowledge sharing intention, with path coefficients of $0.332,0.205,0.397$, and 0.340 , respectively. According to Table 4, we found that the effect of cognitive attitude on knowledge sharing intention was reduced $(0.205 \rightarrow 0.050)$ and was insignificant. The effect of affective attitude on knowledge sharing intention was reduced $(0.332 \rightarrow 0.163)$ but was still significant. The effect of self-efficacy on knowledge sharing intention was reduced $(0.397 \rightarrow 0.201)$ but was still significant. The effect of moral norm on knowledge sharing intention was reduced $(0.340 \rightarrow 0.208)$ but was still significant. We further used variance accounted for (VAF), as suggested by Hair et al. (2014), to determine the size of the indirect effect in relation to the total effect. Full mediation will occur when VAF is larger than 0.8. Partial mediation will occur when VAF is larger than 0.2 and less than 0.8. The VAF values for affective attitude, cognitive attitude, self-efficacy, and moral norm are $0.61,0.83,0.59$, and 0.48 , respectively. According to the results of Baron \& Kenny (1986) and Hair et al. (2014), we can confirm that: 1) desire fully mediates the relationship between cognitive attitude and knowledge sharing intention; 2) desire partially mediates the relationship between affective attitude and knowledge sharing intention; 3) desire partially mediates the relationship between self-efficacy and knowledge sharing intention; and 4) desire partially mediates the relationship between moral norm and knowledge sharing intention. Thus, $H_{3}$ are partially supported and $H_{4}$ are supported.

\subsection{Model's Predictive Relevance}

We used Stone-Geisser's $Q^{2}$ to assess the model's predictive relevance. A $Q^{2}$ value of greater than zero indicates that the exogenous constructs have predictive relevance for the endogenous construct under consideration (Henseler et al., 2009). We used a blindfolding technique to obtain cross-validated redundancy measures $\left(Q^{2}\right)$ for each endogenous construct (Hair et al., 2014); the average $Q^{2}$ value across all endogenous constructs was 0.56 , indicating that our research model had adequate predictive relevance.

\section{Discussions}

This study use two-component TPB to predict knowledge sharing intention and to address two major gaps in the literature of the TPB. First, we confirmed the effect of two-component TPB with moral norm on knowledge sharing intention. This finding addresses Ajzen's (1991) concern about more research to theory broadening regarding the TPB. Second, we supported the mediation of desire on the relationships between affective and cognitive attitudes, self-efficacy, moral norm and knowledge sharing intention. Due to discrepancy about the mediation of desire on the relationships between core TPB variables and intention reported in the literature, our findings may provide a bridge between such variables and intention by discovering the mediation of desire on the relationship between two-component TPB with moral norm and intention.

\subsection{The Effects of Affective and Cognitive Attitudes, Self-Efficacy, Moral Norm on Intention}

The first goal of this study is to empirically examine whether the two-component TPB combined with moral norm can predict knowledge sharing intention. Table 4 shows that self-efficacy is the most important factor in predicting knowledge sharing intention, followed by moral norm, affective and cognitive attitudes. In other words, when an individual has affective and cognitive attitudes toward knowledge sharing, has confidence on knowledge sharing and has moral obligation toward knowledge sharing, he or she is likely to display an intention to share knowledge. Our results are consistent with TPB literature with respect to the effects of affective attitude, cognitive attitudes, self-efficacy, and moral norm on intention. From a theoretical implication, our findings may contribute to the literature of knowledge sharing by discovering the importance of personal factors (attitudes, PBC, moral norm) rather than social factors (e.g., subjective norms) in predicting knowledge sharing intention. To examine the extent to which moral norm contributes to intention, we performed an analysis of $f^{2}$ ef- 
fect size and we found that the $f^{2}$ effect size of the moral norm on intention is 0.217 . The $f^{2}$ values of $0.02,0.15$, and 0.35 indicate an exogenous construct's small, medium, or large effect, respectively, on an endogenous construct. In other words, moral norm has a medium effect size, thereby suggesting that moral norm is an important variable in predicting knowledge sharing intention. Most KM research considers knowledge a private good. When such a perception exists, individuals share their knowledge to receive tangible benefits (e.g., a bonus) or intangible benefits (e.g., image). In contrast, several researchers (e.g., Ardichvili et al., 2003; Connolly et al., 1992; Wasko \& Faraj, 2002) regarded knowledge as a public good, belonging not to the individual but to the whole organization. These researchers indicated when such a perception exists, individuals can improve their work performance by using shared knowledge from others, and this usage does not reduce the value of shared knowledge to others. However, under this condition, free-riders may consume knowledge (a public good) without contributing to its provision. If individuals are rational, they may not contribute their knowledge to the organization. This is the so called public-good dilemma in the knowledge sharing process (Cabrera \& Cabrera, 2002). Our results may provide an explanation for why individuals still contribute their knowledge under the public-good dilemma. Our results indicated that the average score of moral norm is 5.27. This means that the majority of the respondents in this study viewed knowledge sharing as an ethical behavior. Thus, the majority of the respondents were motivated by moral obligation rather than self-interest and heightened their desires to form intentions to share knowledge even in the public-good dilemma. From a theoretical implication, we believe that knowledge may be considered a public good when a perception of moral obligation exists. This may help to expand the application of moral norm in knowledge management research.

From a managerial implication, managers need to strengthen employees' attitudes, self-efficacy, and moral norm in order to entail employees' intentions to share knowledge. Many approaches have been developed for inducing positive attitude change such as enhancing individuals' motivations or moods, providing training programs, and encouraging two-sided communication. We suggest the managers to adopt these approaches to induce employees' positive attitudes toward knowledge sharing. Managers also could develop a reward program to encourage employees to maintain positive attitude change because attitude change may be unstable or temporary (Thompson \& Hunt, 1996). Individuals may rely, in part, on the opinions of others in forming judgments about their abilities. Thus, Bandura (1986) indicated that encouragement from others may strengthen self-efficacy. To strengthen employees' perceived abilities toward sharing knowledge, we suggest the managers to encourage employees to develop close friendship ties. Such friendship ties may help employees to interact with others and obtain others' recognitions with respect to the importance of their own expertise, thereby increasing employees' confidence in sharing knowledge. To identify the influence of moral norm on a behavior, Schwartz (1970) mentioned that a person must be aware that his potential actions have consequences for the welfare of another. Thus, we suggest the manager to deliver information via email, bulletin board, or meeting to tell employees the importance of sharing knowledge and this sharing can further make organizations better. Such information may elicit employees’ duties and thereby strengthen their moral obligations regarding knowledge sharing.

\subsection{The Role of the Desire on Predicting Intention}

The second goal of this study is to examine whether the constructs of the two-component TPB and moral norm can indirectly influence knowledge sharing intention through desire. To examine the importance of desire in our research model, we performed an analysis of $f^{2}$ effect size and we found that the $f^{2}$ effect size of desire on intention is 2.236. In other words, desire has a large effect size, thereby suggesting that desire should not be ignored in predicting knowledge sharing intention. The results of variance accounted for (VAF) we reported previously support that $83 \%$ of the cognitive attitude's effect on intention is explained via desire, $61 \%$ of the affective attitude's effect on intention is explained via desire, $59 \%$ of the self-efficacy's effect on intention is explained via desire, and $48 \%$ of the moral norm's effect on intention is explained via desire. From a theoretical implication, the results of the VIF also confirm that desire plays an important mediator role on the cognitive factors' effects on knowledge sharing intention.

In addition, Perugini \& Bagozzi (2001) claimed that desire fully mediates the relationships between TPB core variables (attitude, subjective norm and PBC) and intention in their MGB model. However, several studies (e.g., Kovac \& Rise, 2011; Leone et al., 2004; Shaw et al., 2007) did not completely support their argument and reported inconsistent findings. Thus, the mediating role of desire may need to be further examined and discussed. Unlike previous studies, our study used the two-component TPB to clarify further the mediating effect of desire. 


\subsection{The Mediation of the Desire on the Effects of Affective Attitude and Cognitive Attitude on Intention}

Our results reported that desire mediates the relationships between the two components attitude and intention. More specifically, we found that desire fully mediates the relationship between cognitive attitude and intention, and partially mediates the relationship between affective attitude and intention. These findings imply that cognitive attitude is considered a construct lacking strong motivational content, by itself unable to fully activate intention to share knowledge. In contrast, affective attitude is considered capable of directly energizing intention to share knowledge. Previous studies (e.g., Perugini \& Bagozzi, 2001; Leone et al., 2004) indicated that desire fully mediates the relationship between attitude and intention. Our findings provide clearer evidence to show that the effect of cognitive component of attitude rather than the affective component of attitude on intention may be fully mediated by desire. Cognitive attitude represents cognitive evaluation (e.g., useful/useless) toward a behavior. Although employees perceive that knowledge sharing is useful for work performance, this perception does not necessarily imply connections to knowledge sharing intention because cognitive attitude may still remain a static estimation of the likelihood of particular outcomes from performing knowledge sharing. The study of Kovac \& Rise (2011) implied that without desire at work, attitude might frequently be representative of the self-detached evaluations on a favor-disfavor continuum, which are not embedded in commitment toward intended action. Thus, the cognitive evaluation aspects of knowledge sharing need to be transformed into personal desire, which in turn, entails an intention to share knowledge. Our results indicated that affective attitude still exerts a direct effect on intention when desire is entered into the relationship between affective attitude and intention. The affective attitude is the direct emotional response (e.g., unenjoyable/enjoyable) to the thought of a behavior. Affective responses with respect to knowledge sharing, for example, could be expressions of liking for knowledge sharing. Such liking may reflect intrinsic motivation that connects to behavioral intention. Based on these considerations, affective attitude might represent strong motivational force and is able to fully activate intention.

\subsection{The Mediation of the Desire on the Effect of Self-Efficacy on Intention}

As indicated in the previous discussion, there are inconsistent results for whether the effect of PBC on intention can be mediated by desire. Our results clearly indicated that desire partially mediates the effect of self-efficacy on intention; however, desire does not mediate the effect of perceived controllability on intention. That is, self-efficacy is considered capable of directly energizing intention when desire is entered into the relationship between self-efficacy and intention. Self-efficacy has an impact by itself on forming intention, which is likely in light of their self-reinforcing nature. The study of Wood \& Bandura (1989) indicated that when an individual has a high level of self-reinforcement, he or she believes that he or she can mobilize the motivation, cognitive resources, and courses of action needed to meet a given set of situational demands. From a theoretical implication, a high self-efficacy individual may anticipate that he or she can be rewarded from his or her capability by performing knowledge sharing behavior successfully and thereby build his or her intention to share knowledge upon own self-efficacy perceptions. Based on these considerations, self-efficacy might represent a strong motivational force and be able to fully activate intention.

\subsection{The Mediation of the Desire on the Effect of Moral Norm on Intention}

Our results indicated that desire partially mediates the effect of moral norm on intention. That is, moral norm is considered capable of directly energizing intention when desire is entered into the relationship between moral norm and intention. An individual may have intention to act when he or she has an internal feeling with respect to moral obligation for specific actions. That is, moral norm is closely related to self-related consideration in terms of the moral worth to the self rather than behavioral outcomes. Godin et al. (2005) mentioned that moral norm is an expression of the core self and reflects an autonomous motivation to act. Deci and Ryan (1987) mentioned that autonomy connotes an inner endorsement of one's actions, the sense that they emanate from oneself and are one's own. From a theoretical implication, Schwartz (1977) suggested that individuals with an autonomous, internally controlled source of motivation are more likely to achieve goals than are individuals who are motivated by external sources of control. In other words, people who based their intentions to act on moral norm should be especially likely to realize those intentions. Unlike Western individualism, Confucian ethics often 
dominates Chinese behaviors. Confucian ethics are based on concepts of personal duties and social goals rather than on personal rights (Bedford \& Hwang, 2003). In a cross-cultural study, Ma (1989) found that Chinese, taught to be affective and altruistic to their group members, showed a stronger orientation to perform affective and altruistic acts than did Western people. From the viewpoints of the Confucianism, the duty-based ethics of Confucian may encourage Chinese to exhibit positive behaviors such as knowledge sharing behavior in an organization because Chinese are likely to consider knowledge sharing as personal duties for making the organization better. Based on these considerations, moral importance to perform a behavior may be easier to transfer into an intention to do so. Therefore, moral norm might represent a strong motivational force able to fully activate intention.

\section{Conclusions and Limitations}

The purpose of this study is to use the two-component TPB model with moral norm in the area of knowledge sharing. Our results indicated that moral norm cannot be ignored in exploring knowledge sharing intention. In addition, desire mediates the relationships between affective attitude, cognitive attitude, self-efficacy, moral norm and knowledge sharing intention. As with all other studies, this study is not without its limitations.

The first limitation concerns the generalizability of our findings. Although we deliberately designed our study, we do not claim that our results will hold equally well in the context of other industries. Future research would benefit from using diverse samples of other industries to strengthen the cross validation of the findings. The second limitation concerns survey bias. Because we focused on the Credit Cooperation to investigate employees' perceptions toward knowledge sharing intention, our results may be likely to be threatened by self-selection bias or sample representativeness. Thus, our results should be limited to interpret the perceptions of participants who served in the Credit Cooperation. We suggest that future researchers focus on more financial institutes to investigate employees' perceptions toward knowledge sharing intention. By doing so, a wider sample may be selected and thus to reduce self-selection bias. The third limitation concerns the theory broadening. Like traditional TPB model, our research model emphasizes on cognitive factors in predicting intentions. Future research may incorporate other factors such as emotional factors to predict knowledge sharing intention. Previous studies (e.g., Parker et al., 1995; Perugini \& Bagozzi, 2001) suggested the importance of anticipated emotions on predicting intention. Thus, we suggest that future research may account for positive anticipated emotion such as anticipated proud or negative anticipated emotion such as anticipated regret in predicting knowledge sharing intention. This research provides an empirical viewpoint for knowledge sharing intention to consider in emphasizing the linkage between desires, morality and TPB factors. Given the importance of knowledge sharing, we hope that our findings will be valuable to others who engage in developing the theory and practice of knowledge sharing.

\section{References}

Ajzen, I. (1991). The Theory of Planned Behavior. Organizational Behavior and Human Decision Processes, 50, $179-211$. http://dx.doi.org/10.1016/0749-5978(91)90020-T

Ajzen, I. (2002). Constructing a TPB Questionnaire: Conceptual and Methodological Considerations. http://www.uni-bielefeld.de/ikg/zick/ajzen\%20construction\%20a\%20tpb\%20questionnaire.pdf

Ardichvili, A., Page, V., \& Wentling, T. (2003). Motivation and Barriers to Participation in Virtual Knowledge-Sharing Communities of Practice. Journal of Knowledge Management, 7, 64-77. http://dx.doi.org/10.1108/13673270310463626

Armitage, C., \& Conner, M. (2001). Efficacy of the Theory of Planned Behaviour: A Meta-Analytic Review. British Journal of Social Psychology, 40, 471-499. http://dx.doi.org/10.1348/014466601164939

Bagozzi, R. \& Dholakia, U. (2006). Open Source Software User Communities: A Study of Participation in Linux User Groups. Management Science, 52, 1099-1115. http://dx.doi.org/10.1287/mnsc.1060.0545

Bagozzi, R. (1992). The Self-Regulation of Attitudes, Intentions, and Behavior. Social Psychology Quarterly, 55, $178-204$. http://dx.doi.org/10.2307/2786945

Baron, R., \& Kenny, D. (1986). The Moderator-Mediator Variable Distinction in Social Psychological Research: Conceptual, Strategic, and Statistical Considerations. Journal of Personality and Social Psychology, 51, 1173-1182. http://dx.doi.org/10.1037/0022-3514.51.6.1173

Bedford, O., \& Hwang, K. K. (2003). Guilt and Shame in Chinese Culture: A Cross-Cultural Framework from the Perspective of Morality and Identity. Journal for the Theory of Social Behaviour, 33, 127-144. http://dx.doi.org/10.1111/1468-5914.00210 
Bock, G-W., Zmud, R., Kim, Y-G., \& Lee, J-N. (2005). Behavioral Intention Formation in Knowledge Sharing: Examining the Roles of Extrinsic Motivators, Social-Psychological Forces, and Organizational Climate. MIS Quarterly, 29, 87-111.

Cabrera, A., \& Cabrera, E. (2002). Knowledge-Sharing Dilemmas. Organization Studies, 23, 687-710. http://dx.doi.org/10.1177/0170840602235001

Chatzoglou, P., \& Vraimaki, E. (2009). Knowledge-Sharing Behaviour of Bank Employees in Greece. Business Process Management Journal, 15, 245-266. http://dx.doi.org/10.1108/14637150910949470

Chen, I., \& Chen, N. S. (2009). Examining the Factors Influencing Participants' Knowledge Sharing Behavior in Virtual Learning Communities. Journal of Educational Technology \& Society, 12, 134-148.

Chiu, C. M., Hsu, M. H., \& Wang, E. (2006). Understanding Knowledge Sharing in Virtual Communities: An Integration of Social Capital and Social Cognitive Theories. Decision Support System, 42, 1872-1888. http://dx.doi.org/10.1016/j.dss.2006.04.001

Chu, P. Y., \& Chiu, J. F. (2003). Factors Influencing Household Waste Recycling Behavior: Test of an Integrated Model. Journal of Applied Social Psychology, 33, 604-626. http://dx.doi.org/10.1111/j.1559-1816.2003.tb01915.x

Conner, M., \& Armitage, C. (1998). Extending the Theory of Planned Behavior: A Review and Avenues for Further Research. Journal of applied social psychology, 28, 1429-1464. http://dx.doi.org/10.1111/j.1559-1816.1998.tb01685.x

Conner, M., \& Sparks, P. (2005). The Theory of Planned Behavior. In M. Conner, \& P. Norman (Eds.), Predicting Health Behaviour: Research and Practice with Social Cognition Models (pp.121-162). Buckingham: Open University Press.

Conner, M., Lawton, R., \& Parker, D. (2007). Application of the Theory of Planned Behaviour to the Prediction of Objectively Assessed Breaking of Posted Speed Limits. British Journal of Psychology, 98, 429-453. http://dx.doi.org/10.1348/000712606X133597

Connolly, T., Thorn, B., \& Heminger, A. (1992). Discretionary Databases as Social Dilemmas. In W. B. G. Liebrand, D. M. Messick, \& H. A. M. Wilke (Eds.), Social Dilemmas: Theoretical Issues and Research Findings (pp. 199-208). New York: Pergamon Press.

Courneya, K., Conner, M., \& Rhodes, R. (2006). Effects of Different Measurement Scales on the Variability and Predictive Validity of the Two-Component Model of the Theory of Planned Behavior in the Exercise Domain. Psychology \& Health, 21, 557-570. http://dx.doi.org/10.1080/14768320500422857

Davis, W. (1984). A Causal Theory of Intending. American Philosophical Quarterly, 21, 43-54.

Elliott, M., \& Ainsworth, K. (2012). Predicting University Undergraduates’ Binge-Drinking Behavior: A Comparative Test of the One- and Two-Component Theories of Planned Behavior. Addictive Behaviors, 37, 92-101.

http://dx.doi.org/10.1016/j.addbeh.2011.09.005

Engelmann, T., \& Friedrich, H. (2011). Fostering Sharing of Unshared Knowledge by having Access to the Collaborators' Meta-Knowledge Structures. Computers in Human Behavior, 27, 2078-2087.

http://dx.doi.org/10.1016/j.chb.2011.06.002

Fazio, R. (1995). Attitudes as Object-Evaluation Associations: Determinants, Consequences, and Correlates of Attitude Accessibility. In R. E. Petty, \& J. A. Krosnick (Eds.), Attitude Strength: Antecedents and Consequences (pp. 247-282). Hillsdale, NJ: Erlbaum.

Fen, Y., \& Sabaruddin, N. (2008). An Extended Model of Theory of Planned Behaviour in Predicting Exercise Intention. International Business Research, 1, 108-122.

Fukuyama, H., Guerra, R., \& Weber, W. L. (1999). Efficiency and Ownership: Evidence from Japanese Credit Cooperatives. Journal of Economics and Business, 51, 473-487. http://dx.doi.org/10.1016/S0148-6195(99)00020-X

Gefen, D., Straub, D., \& Boudreau, M. C. (2000). Structural Equation Modeling Technique and regression: Guidelines for Research Practices. Communications for AIS, 7, 1-78.

Godin, G., Conner, M., \& Sheeran, P. (2005). Bridging the Intention-Behaviour Gap: The Role of Moral Norm. British Journal of Social Psychology, 44, 497-512. http://dx.doi.org/10.1348/014466604X17452

Haenlein, M., \& Kaplan, A. (2004). A Beginner’s Guide to Partial Least Squares Analysis. Understanding Statistics, 3, 283297. http://dx.doi.org/10.1207/s15328031us0304_4

Hagger, M., \& Chatzisarantis, N. (2005). First- and Higher-Order Models of Attitudes, Normative Influence, and Perceived Behavioural Control in the Theory of Planned Behaviour. British Journal of Social Psychology, 44, 513-535. http://dx.doi.org/10.1348/014466604X16219

Hair, J., Hult, T., Ringle, C., \& Sarstedt, M. (2014). A Primer on Partial Least Squares Structural Equation Modeling (PLS-SEM). Thousand Oaks, CA: Sage Publications, Inc.

Hair, J., Ringle, C., \& Sarstedt, M. (2011). PLS-SEM: Indeed a Silver Bullet. The Journal of Marketing Theory and Practice, 19, 139-152. http://dx.doi.org/10.2753/MTP1069-6679190202

Han, H., \& Ryu, K. (2012). The Theory of Repurchase Decision-Making (TRD): Identifying the Critical Factors in the 
Post-Purchase Decision-Making Process. International Journal of Hospitality Management, 31, 786-797. http://dx.doi.org/10.1016/j.ijhm.2011.09.015

Henseler, J., Dijkstra, T., Sarstedt, M., Ringle, C., Diamantopoulos, A., Straub, D., Ketchen, D., Hair, J., Hult, T., \& Calantone, R. (2014). Common Beliefs and Reality about PLS Comments on Rönkkö and Evermann. Organizational Research Methods, 17, 182-209. http://dx.doi.org/10.1177/1094428114526928

Henseler, J., Ringle, C., \& Sinkovics, R. (2009). The Use of Partial Least Squares Path Modeling in International Marketing. Advance in International Marketing, 20, 277-319. http://dx.doi.org/10.1108/S1474-7979(2009)0000020014

Hsu, M. H., Ju, T., Yen, C. H., \& Chang, C. M. (2007). Knowledge Sharing Behavior in Virtual Communities: The Relationship between Trust, Self-Efficacy, and Outcome Expectations. International Journal of Human-Computer Studies, 65, 153-169. http://dx.doi.org/10.1016/j.ijhcs.2006.09.003

Kankanhalli, A., Tan, B., \& Wei, K. K. (2005). Contributing Knowledge to Electronic Knowledge Repositories: An Empirical Investigation. MIS Quarterly, 29, 113-143.

Kovac, V., \& Rise, J. (2011). The Role of Desire in the Prediction of Intention: The Case of Smoking Behavior. Swiss Journal of Psychology, 70, 141-148. http://dx.doi.org/10.1024/1421-0185/a000049

Kuo, F. Y., \& Young, M. L. (2008). Predicting Knowledge Sharing Practices through Intention: A Test of Competing Models. Computers in Human Behavior, 24, 2697-2722. http://dx.doi.org/10.1016/j.chb.2008.03.015

Lam, S. P. (1999). Predicting Intentions to Conserve Water from the Theory of Planned Behavior, Perceived Moral Obligation, and Perceived Water Right. Journal of Applied Social Psychology, 29, 1058-1071. http://dx.doi.org/10.1111/j.1559-1816.1999.tb00140.x

Langdridge, D., Sheeran, P., \& Connolly, K. (2007). Analyzing Additional Variables in the Theory of Reasoned Action. Journal of Applied Social Psychology, 37, 1884-1913. http://dx.doi.org/10.1111/j.1559-1816.2007.00242.x

Leone, L., Perugini, M., \& Ercolani, A. (1999). A Comparison of Three Models of Attitude-Behavior Relationships in the Studying Behavior Domain. European Journal of Social Psychology, 29, 161-189. http://dx.doi.org/10.1002/(SICI)1099-0992(199903/05)29:2/3<161::AID-EJSP919>3.0.CO;2-G

Leone, L., Perugini, M., \& Ercolani, A. (2004). Studying, Practicing, and Mastering: A Test of the Model of Goal-Directed Behavior (MGB) in the Software Learning Domain. Journal of Applied Social Psychology, 34, 1945-1973. http://dx.doi.org/10.1111/j.1559-1816.2004.tb02594.x

Lin, H. F., \& Lee, G. G. (2004). Perceptions of Senior Managers toward Knowledge-Sharing Behaviour. Management Decision, 42, 108-125. http://dx.doi.org/10.1108/00251740410510181

Ma, H. K. (1989). Moral Orientation and Moral Judgment in Adolescents in Hong Kong, Mainland China and England. Journal of Cross-Cultural Psychology, 20, 152-177. http://dx.doi.org/10.1177/0022022189202003

Perugini, M., \& Bagozzi, R. (2001). The Role of Desires and Anticipated Emotions in Goal-Directed Behaviours: Broadening and Deepening the Theory of Planned Behaviour. British Journal of Social Psychology, 40, 79-98. http://dx.doi.org/10.1348/014466601164704

Perugini, M., \& Conner, M. (2000). Predicting and Understanding Behavioral Volitions: The Interplay between Goals and Behaviors. European Journal of Social Psychology, 30, 705-731. http://dx.doi.org/10.1002/1099-0992(200009/10)30:5<705::AID-EJSP18>3.0.CO;2-\#

Rhodes, R., \& Courneya, K. (2003). Investigating Multiple Components of Attitude, Subjective Norm, and Perceived Control: An Examination of the Theory of Planned Behaviour in the Exercise Domain. British Journal of Social Psychology, 42, 129-146. http://dx.doi.org/10.1348/014466603763276162

Rhodes, R., Courneya, K., \& Jones, L. (2003). Translating Exercise Intentions into Behavior: Personality and Social Cognitive Correlates. Journal of Health Psychology, 8, 447-458. http://dx.doi.org/10.1177/13591053030084004

Richetin, J., Perugini, M., Adjali, I., \& Hurling, R. (2008). Comparing Leading Theoretical Models of Behavioral Predictions and Post-Behavior Evaluations. Psychology \& Marketing, 25, 1131-1150. http://dx.doi.org/10.1002/mar.20257

Ringle, C., Wende, S., \& Will, A. (2005). Smart PLS 2.0. http://www.smartpls.de

Rivis, A., Sheeran, P., \& Armitage, C. (2009). Expanding the Affective and Normative Components of the Theory of Planned Behavior: A Meta-Analysis of Anticipated Affect and Moral Norms. Journal of Applied Social Psychology, 39, 2985-3019. http://dx.doi.org/10.1111/j.1559-1816.2009.00558.x

Ryu, S., Ho, S. H., \& Han, I. (2003). Knowledge Sharing Behavior of Physicians in Hospitals. Expert Systems with Applications, 25, 113-122. http://dx.doi.org/10.1016/S0957-4174(03)00011-3

Schwartz, S. H. (1970). Elicitation of Moral Obligation and Self-Sacrificing Behavior: An Experimental Study of Volunteering to Be a Bone Marrow Donor. Journal of Personality and Social Psychology, 15, 283-293.

http://dx.doi.org/10.1037/h0029614

Shaw, D., Shiu, E., Hassan, L., Bekin, C., \& Hogg, G. (2007). Intending to be Ethical: An Examination of Consumer Choice 
in Sweatshop Avoidance. Advances in Consumer Research, 34, 31-38.

Sparks, J. (1994). Machiavellianism and Personal Success in Marketing: The Moderating Role of Latitude of Improvisation. Journal of the Academy of Marketing Science, 22, 393-400. http://dx.doi.org/10.1177/0092070394224008

Taylor, S., Ishida, C., \& Wallace, D. (2009). Intention to Engage in Digital Piracy: A Conceptual Model and Empirical Test. Journal of Service Research, 11, 246-262. http://dx.doi.org/10.1177/1094670508328924

Thompson, R. C., \& Hunt, J. G. J. (1996). Inside the Black Box of Alpha, Beta, and Gamma Change: Using a Cognitive-Processing Model to Assess Attitude Structure. Academy of Management Review, 21, 655-690. http://dx.doi.org/10.2307/258998

Wasko, M., \& Faraj, S. (2000). It Is What One Does: Why People Participate and Help Others in Electronic Communities of Practice. The Journal of Strategic Information Systems, 9, 155-173. http://dx.doi.org/10.1016/S0963-8687(00)00045-7

Wasko, M., \& Faraj, S. (2005). Why Should I Share? Examining Social Capital and Knowledge Contribution in Electronic Networks of Practice. MIS Quarterly, 29, 35-57.

Wood, R., \& Bandura, A. (1989). Social Cognitive Theory of Organizational Management. Academy of management Review, 14, 361-384. 